\title{
CONSERVAÇÃO PÓS-COLHEITA DO MARACUJÁ DOCE COM CERAS COMERCIAIS
}

\author{
ALESSANDRA PEREIRA DA SILVA* \\ SUMAYA ALVES LACERDA** \\ ROGÉRIO LOPES VIEITES***
}

Verificou-se o efeito do uso de ceras comerciais em maracujá doce (Passiflora alata Dryander). Após a desinfecção dos frutos com thiabendazol $(0,5 \mathrm{~g} / \mathrm{L})$, estes foram secos à sombra, e imersos por 1 minuto, em diferentes tipos de ceras comerciais, todas na diluição 1:1 (constituindo os tratamentos: 1) Testemunha; 2) Cera Sta-fresh; 3) Cera Fruit wax; 4) Cera Sparcitrus; e 5) Cera Citrosol). Os frutos foram avaliados semanalmente quanto à perda de peso, textura, rendimento de suco, sólidos solúveis totais, acidez total titulável e pH. O delineamento experimental adotado foi 0 inteiramente casualizado, com 5 tratamentos e 3 repetições. Após 28 dias de armazenamento, sob refrigeração $\left(9^{\circ} \mathrm{C}\right)$, verificou-se que todas as ceras utilizadas foram eficientes no controle da perda de peso dos frutos. As ceras Sparcitrus e Citrosol foram as que mais se destacaram por reduzirem a perda de peso dos frutos em 53,31\% e $39,67 \%$, respectivamente, quando comparadas ao tratamento testemunha. O tratamento com cera Citrosol foi o que proporcionou maior manutenção da firmeza dos frutos, apresentando ao final do período, os valores mais altos de textura e os menores teores de acidez total titulável. Ao final do período estudado não houve diferença estatística no rendimento de suco e no teor de sólidos solúveis totais dos frutos nos diversos tratamentos testados. Os frutos tratados com cera Sta-fresh obtiveram os maiores níveis de $\mathrm{pH}$.

* Eng. Agr., bolsista FAPESP, estudante do Curso de Pós-Graduação em Horticultura, Faculdade de Ciências Agronômicas (FCA), UNESP - Botucatu, SP.

** Eng. Agr., estudante do Curso de Pós-Graduação em Horticultura, FCA - UNESP, Botucatu, SP.

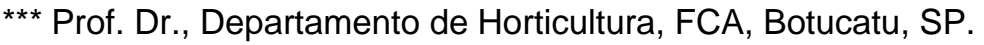




\section{INTRODUÇÃO}

No Brasil, a partir da década de 70 , ocorreu incremento na produção de maracujá, sendo a variedade amarela (Passiflora edulis Sims. f. flavicarpa Deg.) a mais cultivada. Porém, a partir de meados de 1980, o cultivo e a comercialização do maracujá doce (Passiflora alata Dryander), espécie destinada especialmente para consumo in natura, vem aumentando consideravelmente.

Além de apresentar importância pelos frutos que produz, a espécie $P$. alata faz parte das monografias da Farmacopéia Brasileira, integrando a flora medicinal, sendo suas folhas utilizadas no preparo de chás para o tratamento de excitações nervosas, ansiedade e insônia (8).

Segundo descrição apresentada por LEITÃO FILHO \& ARANHA (13), a planta é uma trepadeira vigorosa, totalmente glabra, com caule quadrangulado e fortemente alado. As folhas são oblongo-ovadas, com aproximadamente $14 \mathrm{~cm}$ de comprimento e $10 \mathrm{~cm}$ de largura. As flores são grandes, formadas nas axilas das folhas, de coloração vermelho romã, cuja corona, composta por inúmeros filamentos, apresenta-se com as cores branca, purpúrea e violeta. Os frutos são ovais, obovais ou piriformes, com aproximadamente $10 \mathrm{~cm}$ em seu maior diâmetro, de polpa muito perfumada e um tanto ácida, servindo para preparação de refrescos.

OLIVEIRA et al. (14), em Jaboticabal, compararam cinco procedências de $P$. alata e constataram as seguintes variações em algumas características dos frutos: $\mathrm{pH}$ de 3,48 a 3,56, sólidos solúveis totais de 15,28 a 24,70 ${ }^{\circ}$ Brix, com rendimento de 14,01 a $21,30 \%$ de suco. VASCONCELLOS et al. (17) acompanhando o crescimento semanal dos frutos do maracujazeiro doce nas condições de Botucatu (SP), verificaram que na ocasião da colheita, a porcentagem de suco foi $12,49 \%$, com valor médio de $0,76 \%$ de ácido cítrico e máximo teor de sólidos solúveis (18,45 ํix).

As variações observadas nas características físicas e químicas dos frutos devem-se à diferenças nas condições de clima, solo e práticas culturais, estação do ano e variações sazonais, idade da cultura, estádio de desenvolvimento e maturação dos frutos $(11,15)$. Além disso, algumas características como o tamanho e peso dos frutos, volume de suco e número de sementes estão correlacionadas com a eficiência da polinização e fecundação (1).

ZAPATA (20), durante armazenamento de maracujá amarelo a $6,5^{\circ} \mathrm{C}$ por 4 a 5 semanas, notou queda no rendimento do suco, provavelmente devido à perda de peso verificada no fruto. O teor de sólidos solúveis e a acidez total titulável, no entanto, mantiveram-se constantes. 
ARJONA et al. (2) obtiveram bons resultados na conservação de maracujá amarelo por 30 dias, sob refrigeração a $10{ }^{\circ} \mathrm{C}$ e $85 \%$ de umidade relativa. A perda de peso média observada ao final do período de conservação foi de $26,0 \%$.

VIEITES \& BEZERRA (19) verificaram que, durante 28 dias de armazenamento de maracujá amarelo a temperatura ambiente, os teores de sólidos solúveis passaram de 15,56 para 18,72 ${ }^{\circ}$ Brix, a acidez total titulável passou de 4,18 para 4,07 g de ácido cítrico/100 g de polpa e a firmeza dos frutos passou de 959,94 para 360,24 g/f.

Segundo AWAD (3) a perda de consistência do fruto deve-se a dois fatores principais: perda excessiva de água, levando à diminuição da pressão de turgescência das células, quando o fruto é conservado em atmosferas com umidade relativa baixa, e, decomposição enzimática da lamela média e da parede celular.

Os relatos de aumento na perda de peso, que ocorrem tanto no armazenamento refrigerado, como no ambiente, devem-se à desidratação dos frutos durante o período pós-colheita. A diminuição dos teores de açúcares totais e acidez, também verificadas em ambas condições de armazenamento, ocorrem provavelmente devido à utilização destes compostos como substratos respiratórios (9). Segundo BRODY (4) o teor de ácidos orgânicos, com poucas exceções, tendem à diminuição com 0 amadurecimento dos frutos, em decorrência do processo respiratório ou de sua conversão em açúcares. Como o período do amadurecimento caracteriza-se por apresentar maior atividade metabólica, pode-se dizer que os ácidos orgânicos constituem excelente reserva energética dos frutos, mediante sua oxidação no ciclo de Krebs.

A utilização de ceras comerciais tem sido testada com o intuito de diminuir a perda de peso, proporcionar melhor aparência e prolongar ao máximo a vida pós-colheita de frutos. As ceras comerciais são formulações baseadas em parafina, cera de carnaúba, emulsões em água, gomas, resinas e óleos minerais. Sua aplicação requer certos cuidados, a fim de não causar danos ao produto ou à saúde humana, já que podem conter solventes ou outros componentes danosos (7).

Um ponto crítico na utilização das ceras é sua espessura, uma vez que, quando muito fina, não apresenta efeito contra a perda de umidade, e, se muito grossa, pode aumentar a incidência de doenças e o colapso interno do produto. Porém, se aplicada corretamente pode reduzir a taxa de perda de água em até 50\% (6).

Em trabalho realizado por GAMA et al. (9), com cera autocitrol (25 mL aplicados ao maracujá amarelo com pulverizador manual), foi constado que os valores de perda de peso dos frutos tratados não diferiram 
estatisticamente da testemunha, ambos apresentando aspecto semelhante no final do experimento.

CEREDA (5), com o objetivo de prolongar a vida útil do maracujá amarelo, testou o uso das ceras flavorseal e autocitrol. As ceras estudadas, não se mostraram adequadas, pois provocaram a decomposição rápida da casca do maracujá, favorecendo a instalação de podridões fúngicas.

Este trabalho foi realizado com o objetivo de verificar o efeito do uso de ceras comerciais em maracujá doce e sua eficiência na conservação póscolheita dos frutos.

\section{MATERIAL E MÉTODOS}

O experimento foi conduzido com maracujá da espécie Passiflora alata Dryander, conhecido popularmente por maracujá doce. Os frutos foram colhidos no estádio pré-climatérico, dado pela mudança da coloração verde clara para amarela na parte basal do fruto, mantendo-se cerca de $3 \mathrm{~cm}$ do pedúnculo, conforme recomendações de VASCONCELLOS \& CEREDA (18). Em seguida, foram levados para o Laboratório de Frutas e Hortaliças do Departamento de Horticultura para seleção, homogeneização do lote e retirada total do pedúnculo. As frutas sofreram desinfecção com thiabendazol $(0,5 \mathrm{~g} / \mathrm{L})$, por imersão, em temperatura ambiente por 5 minutos.

Os frutos, após secagem à sombra, foram submetidos aos seguintes tratamentos:

1) Testemunha - sem aplicação de cera;

2) Cera Sta-fresh - os frutos foram imersos na cera comercial Sta-fresh, produzida pela FMC do Brasil;

3) Cera Fruit wax - os frutos foram imersos na cera comercial Fruit wax, produzida pela Spartan do Brasil;

4) Cera Sparcitrus - os frutos foram imersos na cera comercial Sparcitrus, produzida pela Spartan do Brasil;

5) Cera Citrosol - os frutos foram imersos na cera comercial Citrosol, produzida pela Aruá do Brasil.

A diluição utilizada para todas as ceras foi 1:1 (uma parte de água para uma parte do produto). Após a imersão dos frutos na solução por 1 minuto, os mesmos foram secos à sombra.

Os frutos de todos os tratamentos foram armazenados a $9{ }^{\circ} \mathrm{C}$ com $85-90 \%$ de U.R., em estufa incubadora B.O.D., durante 28 dias. 
O experimento foi dividido em 2 grupos: o grupo controle (não destrutivo) e o grupo parcela (destrutivo), ambos avaliados a cada 7 dias de conservação pós-colheita. Os frutos do grupo controle foram avaliados segundo a perda de peso dos frutos em percentagem, por pesagem direta, considerando-se o peso inicial de cada unidade. No grupo parcela, os frutos foram avaliados segundo os seguintes parâmetros: a) textura, medida nos frutos inteiros com casca, utilizando-se Texturômetro Stevens LFRA Texture Analyser, com a ponta de prova -TA 9/1000 e velocidade de penetração de $2,0 \mathrm{~mm} / \mathrm{seg}$, na profundidade de $20 \mathrm{~mm}$; b) rendimento de suco, obtido pela diferença entre o peso do fruto e da casca; c) sólidos solúveis totais (SST), determinado por refratometria, com os resultados expressos em ${ }^{\circ}$ Brix, segundo a metodologia de TRESSLER \& JOSLYN (16); d) acidez total titulável (ATT), determinada mediante titulação de $5 \mathrm{~g}$ de polpa, triturada e diluída com $50 \mathrm{~mL}$ de água destilada, com solução de $\mathrm{NaOH}$ a $0,05 \mathrm{~N}$, padronizada de acordo com técnica preconizada pelo INSTITUTO ADOLFO LUTZ (12), com os resultados expressos em gramas de ácido cítrico/100 g de polpa e, e) $\mathrm{pH}$, com potenciômetro digital (pHmeter tec-2 da Tecnal).

O experimento foi instalado segundo delineamento inteiramente casualizado, com 5 tratamentos e 3 repetições. Os resultados foram submetidos à análise de variância e as médias comparadas pelo Teste de Tukey, ao nível de $5 \%$ de probabilidade, conforme recomendações de GOMES (10).

\section{RESULTADOS E DISCUSSÃO}

Pela Tabela 1 pode-se perceber que, durante o armazenamento ocorreu aumento da perda de peso dos frutos em todos os tratamentos, o que, segundo GAMA et al. (9) deve-se à desidratação dos frutos no período pós-colheita.

Todas as ceras utilizadas foram eficientes no controle da perda de peso dos frutos, já que diferiram estatisticamente da testemunha. No entanto, as ceras Sparcitrus e Citrosol foram as que mais se destacaram por reduzirem a perda de peso dos frutos em $53,31 \%$ e $39,67 \%$, respectivamente, quando comparadas ao tratamento testemunha. Tais resultados corroboram os relatos de CHITARRA \& CHITARRA (6) e EVANGELISTA et al. (7), porém discordam dos de GAMA et al. (9) e CEREDA (5), que não observaram vantagem no uso das ceras.

Os valores médios de perda de peso do maracujá doce verificados no final do período de conservação são semelhantes aos relatados por ARJONA et al. (2), que armazenaram maracujá amarelo a $10^{\circ} \mathrm{C}$. 
TABELA 1 - VARIAÇÃO MÉdIA DE PERDA DE PESO (\%) DOS FRUTOS NOS DIFERENTES TRATAMENTOS

\begin{tabular}{lcccc}
\hline Tratamentos & \multicolumn{4}{c}{ Dias de armazenamento } \\
\cline { 2 - 5 } & 7 & 14 & 21 & 28 \\
\hline Testemunha & $6,21 \mathrm{a}$ & $13,00 \mathrm{a}$ & $20,22 \mathrm{a}$ & $34,33 \mathrm{a}$ \\
Sta-fresh & $3,71 \mathrm{~b}$ & $8,28 \mathrm{~b}$ & $16,56 \mathrm{~b}$ & $29,85 \mathrm{~b}$ \\
Fruit wax & $5,66 \mathrm{a}$ & $11,73 \mathrm{a}$ & $17,60 \mathrm{~b}$ & $24,58 \mathrm{c}$ \\
Sparcitrus & $2,70 \mathrm{c}$ & $6,20 \mathrm{c}$ & $9,82 \mathrm{~d}$ & $16,03 \mathrm{e}$ \\
Citrosol & $3,13 \mathrm{bc}$ & $7,56 \mathrm{bc}$ & $12,90 \mathrm{c}$ & $20,71 \mathrm{~d}$ \\
\hline DMS (\%) & 1,00 & 1,80 & 2,17 & 3,22 \\
CV (\%) & 13,77 & 11,35 & 8,30 & 7,56 \\
\hline
\end{tabular}

Médias seguidas pela mesma letra, na coluna, não diferem significativamente entre si, ao nível de $5 \%$ de probabilidade pelo teste de Tukey.

DMS = Diferença mínima significativa.

$\mathrm{CV}=$ Coeficiente de variação.

Os dados de textura, apresentados na Tabela 2, mostram que no decorrer do período estudado ocorreu decréscimo na firmeza dos frutos. VIEITES \& BEZERRA (19) também relataram queda de 959,94 para 360,24 g/f para maracujá amarelo. Para AWAD (3) esta perda de consistência dos frutos deve-se à perda de água e à decomposição enzimática da lamela média e da parede celular.

\section{TABELA 2 - VARIAÇÃO MÉDIA DA TEXTURA (g/f) DOS FRUTOS NOS DIFERENTES TRATAMENTOS}

\begin{tabular}{lccccc}
\hline Tratamentos & \multicolumn{5}{c}{ Dias de armazenamento } \\
\cline { 2 - 6 } & 0 & 7 & 14 & 21 & 28 \\
\hline Testemunha & $242,67 \mathrm{a}$ & $150,33 \mathrm{c}$ & $142,00 \mathrm{~d}$ & $83,00 \mathrm{~d}$ & $73,67 \mathrm{c}$ \\
Sta-fresh & $242,67 \mathrm{a}$ & $176,33 \mathrm{~b}$ & $165,33 \mathrm{bc}$ & $141,33 \mathrm{~b}$ & $121,67 \mathrm{~b}$ \\
Fruit wax & $242,67 \mathrm{a}$ & $169,00 \mathrm{bc}$ & $149,67 \mathrm{~cd}$ & $122,67 \mathrm{c}$ & $87,33 \mathrm{c}$ \\
Sparcitrus & $242,67 \mathrm{a}$ & $201,00 \mathrm{a}$ & $179,00 \mathrm{~b}$ & $146,00 \mathrm{~b}$ & $123,00 \mathrm{~b}$ \\
Citrosol & $242,67 \mathrm{a}$ & $217,00 \mathrm{a}$ & $212,67 \mathrm{a}$ & $154,00 \mathrm{a}$ & $148,67 \mathrm{a}$ \\
\hline DMS (\%) & 25,01 & 22,96 & 16,39 & 7,77 & 24,96 \\
CV (\%) & 4,48 & 5,46 & 4,20 & 2,61 & 9,79 \\
\hline
\end{tabular}

Médias seguidas pela mesma letra, na coluna, não diferem significativamente entre si, ao nível de $5 \%$ de probabilidade pelo teste de Tukey.

DMS = Diferença mínima significativa.

$\mathrm{CV}=$ Coeficiente de variação. 
Os frutos do tratamento testemunha e os frutos encerados com Fruit wax apresentaram aos 28 dias de conservação pós-colheita, os menores valores de textura observados, seguido pelos frutos tratados com cera Stafresh e Sparcitrus. O tratamento com cera Citrosol foi eficiente na manutenção da firmeza dos frutos, apresentando ao final do período os valores mais altos de textura.

Observa-se, pela Tabela 3, aumento no rendimento de suco dos frutos em todos os tratamentos, porém sem diferença estatística entre eles. Esses dados discordam dos achados por ZAPATA (20), que observou diminuição do rendimento de suco durante o armazenamento de maracujá amarelo a $6,5^{\circ} \mathrm{C}$.

TABELA 3 - VARIAÇÃO MÉDIA DO RENDIMENTO DE SUCO (\%) DOS FRUTOS NOS DIFERENTES TRATAMENTOS

\begin{tabular}{lccccc}
\hline Tratamentos & \multicolumn{5}{c}{ Dias de armazenamento } \\
\cline { 2 - 6 } & 0 & 7 & 14 & 21 & 28 \\
\hline Testemunha & $23,54 \mathrm{a}$ & $31,50 \mathrm{a}$ & $35,08 \mathrm{a}$ & $36,84 \mathrm{a}$ & $38,68 \mathrm{a}$ \\
Sta-fresh & $23,54 \mathrm{a}$ & $26,43 \mathrm{a}$ & $30,89 \mathrm{a}$ & $36,44 \mathrm{a}$ & $37,06 \mathrm{a}$ \\
Fruit wax & $23,54 \mathrm{a}$ & $35,20 \mathrm{a}$ & $36,20 \mathrm{a}$ & $38,06 \mathrm{a}$ & $42,13 \mathrm{a}$ \\
Sparcitrus & $23,54 \mathrm{a}$ & $25,99 \mathrm{a}$ & $27,20 \mathrm{a}$ & $29,33 \mathrm{a}$ & $29,69 \mathrm{a}$ \\
Citrosol & $23,54 \mathrm{a}$ & $26,37 \mathrm{a}$ & $27,49 \mathrm{a}$ & $31,94 \mathrm{a}$ & $33,74 \mathrm{a}$ \\
\hline DMS (\%) & 8,19 & 13,97 & 12,14 & 18,18 & 17,50 \\
CV (\%) & 18,40 & 25,39 & 20,46 & 28,30 & 25,51 \\
\hline
\end{tabular}

Médias seguidas pela mesma letra, na coluna, não diferem significativamente entre si, ao nível de $5 \%$ de probabilidade pelo teste de Tukey.

DMS = Diferença mínima significativa.

$\mathrm{CV}=$ Coeficiente de variação.

Os valores de rendimento de suco do maracujá doce observados no início do experimento são superiores aos relatados por OLIVEIRA et al. (14) e por VASCONCELLOS et al. (17). Segundo AKAMINE \& GIROLAMI (1) as diferenças encontradas no rendimento de suco estão correlacionadas com a eficiência da polinização e fecundação.

Os teores de sólidos solúveis totais, verificados na Tabela 4, aumentaram em todos os tratamentos, no decorrer do período de conservação. Estes dados são semelhantes aos de VIEITES \& BEZERRA (19) para maracujá amarelo, porém discordam dos obtidos por ZAPATA (20), que relata a tendência dos teores de sólidos solúveis de permanecerem constantes durante o armazenamento. No entanto, ao final do período de conservação pós-colheita verificou-se que não houve diferença estatística entre os diversos tratamentos testados. 
O pico no teor de sólidos solúveis foi atingido aos 21 dias para os frutos do tratamento testemunha e com a utilização de cera Sta-fresh, enquanto que, os demais tratamentos apresentaram pico no teor de sólidos solúveis aos 28 dias.

Os teores de sólidos solúveis encontrados no maracujá doce no momento da colheita são inferiores aos relatados por OLIVEIRA et al. (14) e por VASCONCELLOS et al. (17). Porém esta variação pode ser explicada, segundo HOLANDA et al. (11) e RITZINGER et al. (15), pelas diferenças nas condições de clima, solo e práticas culturais, estação do ano e variações sazonais, idade da cultura, estádio de desenvolvimento e maturação dos frutos.

TABELA 4 - VARIAÇÃO MÉDIA DE SÓLIDOS SOLÚVEIS ('Brix) DOS FRUTOS NOS DIFERENTES TRATAMENTOS

\begin{tabular}{lccccc}
\hline Tratamentos & \multicolumn{5}{c}{ Dias de armazenamento } \\
\cline { 2 - 6 } & 0 & 7 & 14 & 21 & 28 \\
\hline Testemunha & $13,28 \mathrm{a}$ & $18,25 \mathrm{a}$ & $19,35 \mathrm{a}$ & $20,49 \mathrm{a}$ & $19,63 \mathrm{a}$ \\
Sta-fresh & $13,28 \mathrm{a}$ & $18,24 \mathrm{a}$ & $19,11 \mathrm{ab}$ & $20,04 \mathrm{a}$ & $19,56 \mathrm{a}$ \\
Fruit wax & $13,28 \mathrm{a}$ & $16,72 \mathrm{a}$ & $18,55 \mathrm{ab}$ & $19,25 \mathrm{ab}$ & $19,71 \mathrm{a}$ \\
Sparcitrus & $13,28 \mathrm{a}$ & $14,31 \mathrm{~b}$ & $16,25 \mathrm{c}$ & $16,71 \mathrm{~b}$ & $17,36 \mathrm{a}$ \\
Citrosol & $13,28 \mathrm{a}$ & $14,41 \mathrm{~b}$ & $17,45 \mathrm{bc}$ & $18,03 \mathrm{ab}$ & $19,61 \mathrm{a}$ \\
\hline DMS (\%) & 3,46 & 1,81 & 1,81 & 2,90 & 2,85 \\
CV (\%) & 9,67 & 4,12 & 3,71 & 5,72 & 5,54 \\
\hline
\end{tabular}

Médias seguidas pela mesma letra, na coluna, não diferem significativamente entre si, ao nível de $5 \%$ de probabilidade pelo teste de Tukey.

DMS = Diferença mínima significativa.

$\mathrm{CV}=$ Coeficiente de variação.

Os dados de acidez total titulável (Tabela 5), decrescentes no decorrer do armazenamento dos frutos, para todos os tratamentos, concordam com os de GAMA et al. (9) e VIEITES \& BEZERRA (19), para maracujá amarelo. Este decréscimo pode ser explicado provavelmente pela utilização dos compostos como substratos respiratórios ou pela conversão em açúcares, como citado em BRODY (4). Porém, estes dados conflitam-se com os de ZAPATA (20), que observou valores constantes de acidez no decorrer do armazenamento de maracujá amarelo. Os frutos do tratamento testemunha e com aplicação da cera Sta-fresh apresentaram os maiores teores de acidez, enquanto o tratamento com a cera Citrosol apresentou os menores teores. Os valores de acidez total titulável, obtidos no início do armazenamento, são inferiores aos relatados por VASCONCELLOS et al. (17) para maracujá doce. 
TABELA 5 - VARIAÇÃO MÉDIA DE ACIDEZ TOTAL TITULÁVEL (\% ÁCIDO CÍTRICO/100g DE POLPA) DOS FRUTOS NOS DIFERENTES TRATAMENTOS

\begin{tabular}{lccccc}
\hline Tratamentos & \multicolumn{5}{c}{ Dias de armazenamento } \\
\cline { 2 - 5 } & 0 & 7 & 14 & 21 & $0,417 \mathrm{a}$ \\
\hline Testemunha & $0,472 \mathrm{a}$ & $0,458 \mathrm{a}$ & $0,422 \mathrm{a}$ & $0,421 \mathrm{a}$ & $0,419 \mathrm{a}$ \\
Sta-fresh & $0,472 \mathrm{a}$ & $0,472 \mathrm{a}$ & $0,424 \mathrm{a}$ & $0,423 \mathrm{a}$ & $0,370 \mathrm{ab}$ \\
Fruit wax & $0,472 \mathrm{a}$ & $0,457 \mathrm{a}$ & $0,418 \mathrm{a}$ & $0,392 \mathrm{~b}$ & $0,350 \mathrm{ab}$ \\
Sparcitrus & $0,472 \mathrm{a}$ & $0,440 \mathrm{a}$ & $0,370 \mathrm{~b}$ & $0,366 \mathrm{bc}$ & $0,295 \mathrm{~b}$ \\
Citrosol & $0,472 \mathrm{a}$ & $0,424 \mathrm{a}$ & $0,357 \mathrm{~b}$ & $0,350 \mathrm{c}$ & 0,10 \\
\hline DMS (\%) & 0,12 & 0,07 & 0,02 & 0,03 & 10,08 \\
CV (\%) & 9,76 & 5,63 & 1,58 & 2,51 & \\
\hline
\end{tabular}

Médias seguidas pela mesma letra, na coluna, não diferem significativamente entre si, ao nível de $5 \%$ de probabilidade pelo teste de Tukey.

DMS = Diferença mínima significativa.

CV = Coeficiente de variação.

Os valores médios de $\mathrm{pH}$ dos frutos, apresentados na Tabela 6, aumentaram com o decorrer do armazenamento em todos os tratamentos. Ao final do período de conservação, observou-se que os frutos do tratamento com a cera Sta-fresh apresentaram índices significativamente superiores, enquanto que, os frutos do tratamento testemunha e com a utilização da cera Fruit wax apresentaram índices significativamente inferiores. No início do período de conservação, os valores encontrados foram semelhantes aos obtidos por OLIVEIRA et al. (14).

\section{TABELA 6 - VARIAÇÃO MÉDIA DE pH DOS FRUTOS NOS DIFERENTES TRATAMENTOS}

\begin{tabular}{lccccc}
\hline Tratamentos & \multicolumn{5}{c}{ Dias de armazenamento } \\
\cline { 2 - 6 } & 0 & 7 & 14 & 21 & 28 \\
\hline Testemunha & $3,37 \mathrm{a}$ & $3,40 \mathrm{c}$ & $3,49 \mathrm{~b}$ & $3,60 \mathrm{c}$ & $4,00 \mathrm{c}$ \\
Sta-fresh & $3,37 \mathrm{a}$ & $3,51 \mathrm{a}$ & $3,66 \mathrm{a}$ & $3,90 \mathrm{a}$ & $4,15 \mathrm{a}$ \\
Fruit wax & $3,37 \mathrm{a}$ & $3,37 \mathrm{c}$ & $3,46 \mathrm{~b}$ & $3,58 \mathrm{c}$ & $3,98 \mathrm{c}$ \\
Sparcitrus & $3,37 \mathrm{a}$ & $3,45 \mathrm{c}$ & $3,49 \mathrm{~b}$ & $3,74 \mathrm{~b}$ & $4,08 \mathrm{~b}$ \\
Citrosol & $3,37 \mathrm{a}$ & $3,44 \mathrm{~b}$ & $3,51 \mathrm{~b}$ & $3,62 \mathrm{c}$ & $4,08 \mathrm{~b}$ \\
\hline DMS (\%) & 0,08 & 0,44 & 0,11 & 0,05 & 0,05 \\
CV (\%) & 0,88 & 0,43 & 1,15 & 0,52 & 0,45 \\
\hline
\end{tabular}

Médias seguidas pela mesma letra, na coluna, não diferem significativamente entre si, ao nível de $5 \%$ de probabilidade pelo Teste de Tukey.

DMS = Diferença mínima significativa.

CV = Coeficiente de variação. 
Após 4 semanas de armazenamento verificou-se que:

- todas as ceras utilizadas foram eficientes no controle da perda de peso dos frutos. No entanto, as ceras Sparcitrus e Citrosol foram a que mais se destacaram por reduzirem a perda de peso dos frutos em $53,31 \%$ e $39,67 \%$, respectivamente, quando comparadas ao tratamento testemunha;

- o tratamento com cera Citrosol foi o que proporcionou maior manutenção da firmeza dos frutos, apresentando ao final do período, os valores mais altos de textura e os menores teores de acidez total titulável;

- não houve diferença estatística no rendimento de suco e no teor de sólidos solúveis totais dos frutos nos diversos tratamentos testados;

- os frutos tratados com cera Sta-fresh obtiveram os maiores níveis de $\mathrm{pH}$, enquanto que, os frutos do tratamento testemunha e com a utilização da cera Fruit wax apresentaram os menores níveis de $\mathrm{pH}$.

\begin{abstract}
The effect of the use of commercial waxes in sweet passion fruit (Passiflora alata Dryander) was verified. After disinfection with thiabendazol $(0.5 \mathrm{~g} / \mathrm{L})$ the fruits were dried in shade, and immerged by 1 minute in several commercial waxes in dilution of 1:1, constituting the treatments: 1) control, 2) Wax Sta-fresh, 3) Wax Fruit, 4) Wax Sparcitrus, and 5) Wax Citrosol. The fruits were weekly evaluated for the following variables: weight loss, texture, amount of juice, total soluble solids, titratable acidity and $\mathrm{pH}$. After 28 days of refrigerated storage $\left(9^{\circ} \mathrm{C}\right)$ it was verified that all waxes were efficient in the control of weight loss. The waxes Sparcitrus and Citrosol granted the best control of weight loss, reducing it by rates of $53.31 \%$ and $39.67 \%$ respectively, when compared to the control treatment. The treatment with wax Citrosol provided the best maintenance of the fruits firmness, presenting after 28 days the highest values of texture and the smallest levels of titratable acidity. At the end of the analyzed period there was no statistical difference in both amount of juice and level of total soluble solids for all tested treatments. The treated fruits with wax Sta-fresh obtained the highest $\mathrm{pH}$ levels.
\end{abstract}

\title{
REFERÊNCIAS BIBLIOGRÁFICAS
}

1 AKAMINE, E.K., GIROLAMI, G. Problems in fruit set in yellow passion fruit. Hawaii Farm Science, v. 5, n. 4, p. 3-5, 1957.

2 ARJONA, H.E., MATTA, F.B., GARNER JUNIOR, J.O. Temperature and storage time affect quality of yellow passion fruit.

HortScience, v. 27, n. 7, p. 809-810, 1992. 
3 AWAD, M. Fisiologia pós-colheita de frutos. São Paulo : Nobel, 1993. $114 \mathrm{p}$.

4 BRODY, A.L. Envasado de alimentos en atmosferas controladas, modificadas y a vacio. Zaragoza: Acribia, 1996. 220 p.

5 CEREDA, E. Observações sobre a conservação "in natura" do maracujá amarelo (Passiflora edulis f. flavicarpa Deg.). Botucatu, 1973. Tese (Doutorado em Ciências) - Faculdade de Ciências Médicas e Biológicas de Botucatu, Universidade Estadual Paulista.

6 CHITARRA, M.I.F., CHITARRA, A.B. Pós-colheita de frutos e hortaliças: fisiologia e manuseio. Lavras : ESAL/FAEPE, 1990. $320 \mathrm{p}$.

7 EVANGELISTA, R.M., CHITARRA, A.B., GOLDONI, J.S., CHITARRA, M.I.F. Efeito da aplicação de ceras comerciais na pós-colheita de manga (Mangifera indica L.) cv. Tommy Atkins. Revista Brasileira de Fruticultura, v. 18, n. 1, p. 105-103, 1996.

8 FREITAS, P.C.D. Possibilidades farmacológicas. In: RUGGIERO, C. Maracujá. Ribeirão Preto : Legis Summa, 1987. p. 210-217.

9 GAMA, F.S.N., MANICA, I., KIST, H.G.K., ACCORSI, M.R. Aditivos e embalagens de polietileno na conservação do maracujá amarelo armazenado em condições de refrigeração. Pesquisa Agropecuária Brasileira, v. 26, n. 3, p. 305-310, 1991.

10 GOMES, F.P. Curso de estatística experimental. 12. ed. Piracicaba : Nobel, 1987. $467 \mathrm{p}$.

11 HOLANDA, L.F.F., SESSA, M.C.M., MAIA, G.A., OLIVEIRA, G.S.F., FIGUEIREDO, R.W. Características físico-químicas do suco de maracujá amarelo cultivado no município de Ubajara, CE. In: CONGRESSO BRASILEIRO DE FRUTICULTURA, 9, 1987, Campinas. Anais... Campinas : S.B.F., 1988. v.2, p. 585-590.

12 INSTITUTO ADOLFO LUTZ. Métodos físicos e químicos para análise de alimentos. 3.ed. São Paulo : Instituto Adolfo Lutz, 1985. $533 \mathrm{p}$.

13 LEITÃO FILHO, H.F., ARANHA, C. Botânica do maracujazeiro. In: SIMPÓSIO DA CULTURA DO MARACUJÁ, 1, 1971, Campinas. Simpósio... Campinas : S.B.F., 1974. p. 1-13. 
14 OLIVEIRA, J.C. RUGGIERO, C., NAKAMURA, K., FERREIRA, F.R. Variações observadas em frutos de Passiflora alata Ait. Proceedings of the Tropical Region American Society for Horticultural Science, v. 25, p. 343-345, 1982.

15 RITZINGER, R., MANICA, I., RIBOLDI, J. Efeito do espaçamento e da época de colheita sobre a qualidade do maracujá amarelo. Pesquisa Agropecuária Brasileira, v. 24, n. 2, p. 241-245, 1989.

16 TRESSLER, D.K., JOSLYN, M.A. Fruits and vegetables juice processing technology. Westport : AVI, 1961. $1028 \mathrm{p}$.

17 VASCONCELLOS, M.A.S., CEREDA, E., ANDRADE, J.M.B., BRANDÃO FILHO, J.U.T. Desenvolvimento de frutos do maracujazeiro doce (Passiflora alata Dryand), nas condições de Botucatu-SP. Revista Brasileira de Fruticultura, v. 15, n. 1, p. 153-158, 1993.

18 VASCONCELLOS, M.A.S., CEREDA, E. O cultivo do maracujá doce. In: SÃO JOSÉ, A.R. Maracujá: produção e mercado. Vitória da Conquista : DFZ/UESB, 1994. cap. 11, p. 71-83.

19 VIEITES, R.L., BEZERRA, L.P. Efeito do sulfato de cálcio e da embalagem de polietileno, na conservação do maracujá amarelo, armazenado em condições de refrigeração. Revista Brasileira de Fruticultura, v. 18, n. 2, p. 235-243, 1996.

20 ZAPATA, L.E.M. El manejo precosecha, cosecha y postcosecha de maracuyá para la exportación. Tecnologia, v. 27, n. 166, p. 7-33. 1987. 